\title{
Gender Differences among IT Professionals in Dealing with Change and Skill Set Maintenance
}

\author{
Brian H. Cameron \\ The Pennsylvania State \\ University, University Park, \\ $P A$, USA \\ bcameron@ist.psu.edu
}

\author{
Loreen Butcher-Powell \\ Bloomsburg University of \\ Pennsylvania, Bloomsburg, \\ $P A$, USA
}

Ipowell@bloomu.edu

\begin{abstract}
One of the greatest challenges facing information technology (IT) managers is adapting to change. IT managers must cope with frequent changes in programming languages and technology platforms, all the while implementing new applications within their organizations (Straub \& Watson, 2001). There are many indicators that this constant change is a challenge for IT professionals and managers. Benemati and Lederer (2001) documented a series of problems that IT professionals experience when attempting to cope with the rapid changes of the field, namely "realizing the potential of new IT while avoiding the associated risks."

This study investigates one particular method for dealing with change and skill set maintenance among IT professionals: technology discussion groups. The study also investigates gender differences in the use of discussion groups. Two hundred and fourteen IT professionals were surveyed on what sort of IT-related activities they devote time to, how much problem-solving they attempt via technology discussion groups with respect to those activities, and their perceived community and organizational benefits to participating in such discussion groups. The study found significant gender differences in perceived value of technology discussion groups.
\end{abstract}

Keywords: gender, information technology, change, discussion groups, discussion forums

\section{Background}

For individual IT professionals, the demands associated with constantly learning and adjusting/updating their skill sets can be stressful and compromise overall productivity in a number of ways (Lee, Trauth, \& Farwell, 1995). On the whole, changes in technology significantly affect overall burnout in IT jobs. Sixty two percent of IT professionals claim to operate in "crisis mode" most or all of the time (Fischer, 1998).

Material published as part of this journal, either on-line or in print, is copyrighted by the Informing Science Institute. Permission to make digital or paper copy of part or all of these works for personal or classroom use is granted without fee provided that the copies are not made or distributed for profit or commercial advantage AND that copies 1) bear this notice in full and 2) give the full citation on the first page. It is permissible to abstract these works so long as credit is given. To copy in all other cases or to republish or to post on a server or to redistribute to lists requires specific permission and payment of a fee. Contact Publisher@InformingScience.org to request redistribution permission.
Given the effect of coping with change among IT professionals, IT managers have to be concerned with methods of keeping employees up-to-date on new technologies, as well as providing some form of infrastructure for answerseeking when problems arise. While academic studies of how organizations manage change and take on the challenges of employee training abounds, there is a dearth of research into the 
strategies employed by IT professionals themselves. Many authors have also focused specifically on women in the IT workforce, but those studies typically address the problems women face in IT, rather than exploring what makes them successful.

Research has sought to identify gender differences that may explain the low participation rate among women in the IT profession, but consistent patterns of differences rarely emerge. Moore (2000) was able to make a connection between low job satisfaction and gender. It was hypothesized that women perceived little benefit to themselves or their organizations in the effort required of them to maintain an updated skill set that would allow them to perform adequately. Further analysis of that data suggests, however, that when controlling for job rank, the gender effect goes away.

While Moore's initial hypothesis is complicated by the introduction of job rank as a variable, there does seem to be agreement that rank is at least somewhat tied to gender, perhaps making this a second-order effect. Many authors have identified and addressed the "glass ceiling" that prevents women in IT (and several other professions as well) from advancing beyond a certain point in rank and wages (Ahuja, 2002; Baroudi \& Igbaria, 1995; Harris \& Wilkinson, 2004; Igbaria \& Baroudi, 1995; Kaminski \& Reilly, 2004; Perrons, 2002; Ranson \& Reeves, 1996; Smits, McLean, \& Tanner, 1993; Sumner \& Niederman, 2003). The potential explanations for the glass ceiling are too numerous to list here, ranging from educational interests at a young age, to gender roles in personal lives, to blatant discrimination.

With respect to the IT field specifically, women tend to enter the professional workforce with less training (Francis, 2000), but tend to demonstrate no significant differences in productivity among high-performing men and women (Smits et al., 1993). This seems to indicate that, despite different educational foundations, women in the workforce are capable of compensating for the difference in background. This may be due, in part, to women's increased willingness to admit to a lack of knowledge or understanding, and to seek help (Baroudi \& Igbaria, 1995; Venkatesh, \& Morris, 2000).

The extent to which women will utilize technology to seek help when confronted with a problem or to meet an information need has been explored by a number of researchers studying overall IT use. Gefen and Straub (1997) found that women and men differed in their perceptions of e-mail, but not their use of it, because differences between genders lie in their expectations for performance. Women place more communicative value on e-mail and are more inclined to give more time and care to composing and reading e-mails. Venkatesh and Morris (2000) were able to identify usage differences between men and women, tied to perceptions and level of adoption. Men's technology usage decisions were strongly influenced by their perception of the usefulness of the technology, while women were more strongly influenced by perceived ease of use.

Venkatesh and Morris' findings on the communicative value of e-mail for women can be extended to information and communication technologies in general, thanks to data collected by national agencies in the United States and Japan and summarized by Ono and Zavodny (2005). They found few gender differences in IT use and skills in the United States, but found that women were considerably more likely than men to form relationships via computer-mediated communication. They found that women tend to more readily perceived connections with other users based on common interests or needs, and that those relationships could be individual (perceiving a connection with a single other user) or social (perceiving a connection or sense of belonging to a group with common interests). Firth, Lawrence, and Clouse (2006) examined online communities and the length of time needed to establish such communities. The authors found that successful communities are typically fully established in less than a year. Dube, Bourhis, and Jacob (2006) investigated virtual communities of practice and how to successfully form such 
communities. They found that successful communities continually fine-tuned their actions toward their audience.

\section{Methodology}

A 32-question survey was developed and administered via the internet. The survey collected background information (gender, professional responsibilities, education, career status, etc.), technology information (time spent on specific technology tasks, resources and practices at the organization, and problem-solving methods), and technology discussion group information (personal and organizational methods for discussing technology issues, membership in technology groups, perceived benefits of participation in technology groups, etc.).

A total of 213 participants completed the survey. There were 116 female respondents and 97 male respondents.

The age range of employees was somewhat evenly distributed among 18-60 year-olds. Eight participants completing the survey were 61 or older.

Nearly all participants (172) indicated that they had attended college. Only 41 had received an Associate's degree, 69 held a Bachelor's degree, and 12 had gone on to a Master's or Ph.D.

\section{Analysis}

Participants were asked to complete a five-point Likert Scale response (Strongly Agree to Strongly Disagree) to participation in technology discussion groups influencing community benefits (skill sets, productivity, job satisfaction, personal satisfaction, personal reputation, and sense of belonging) and organizational benefits (knowledge sharing, collaboration, consensus generating, community reputation, and trust). These responses were analyzed by the following variables: age, gender, education, and technology-specific education.

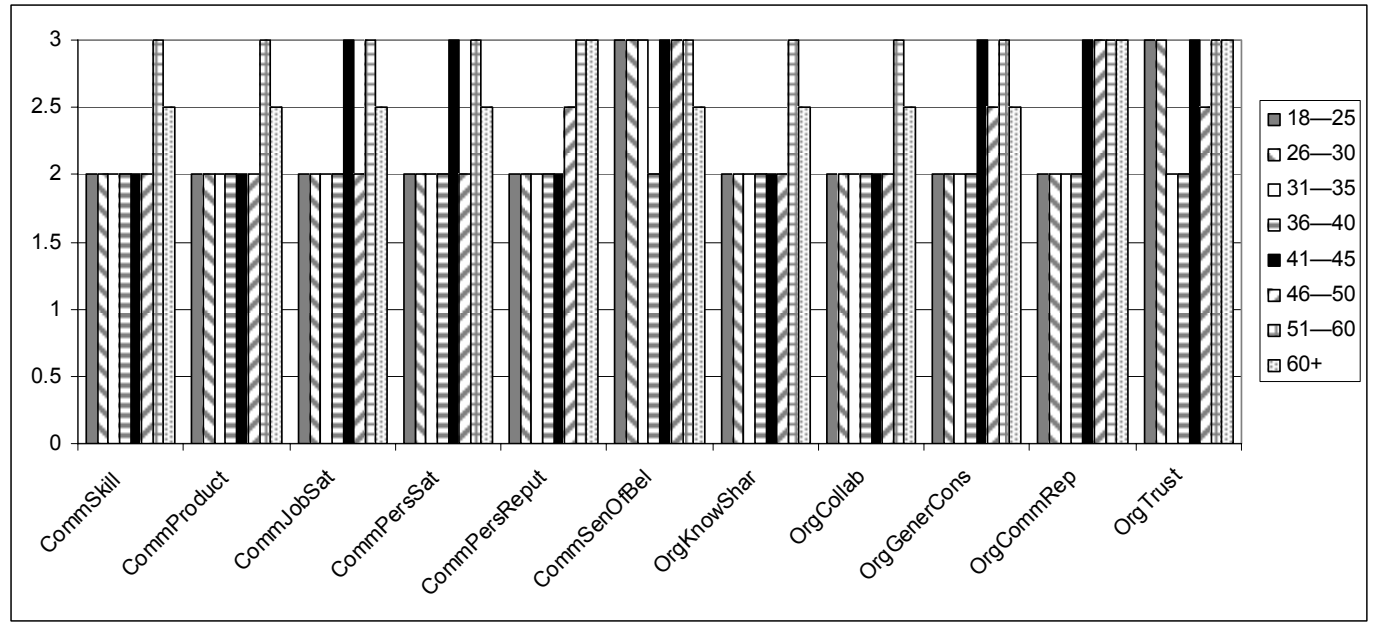

Figure 1: Participation in Technology Discussion Groups by Age

Figure 1 shows that participants in the 51-60 year-old age range highly value participation in technology groups and perceive them to beneficial in all evaluated ways. Apart from that segment of the population, respondents perceive moderate value and do not demonstrate any agedependent patterns.

The interest among 51-60 year-olds could be tied to their job rank and ability, leaving them with more scheduling freedom to participate in technology discussion groups as well as more to contribute to those groups. 


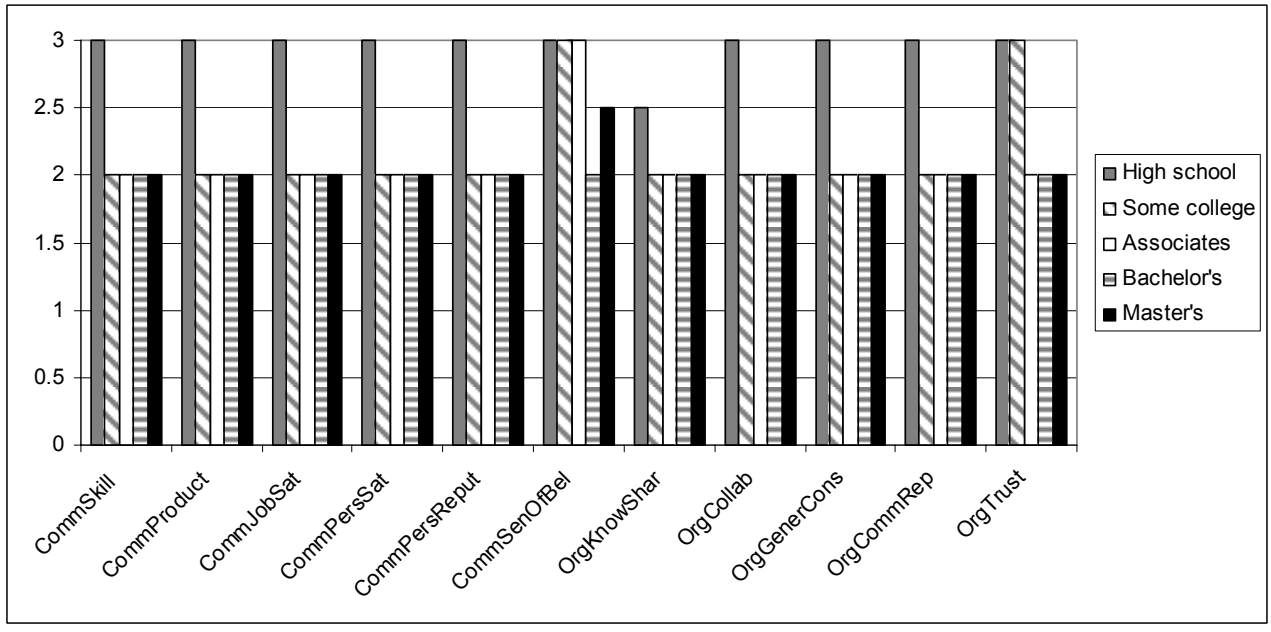

Figure 2: Participation in Technology Groups by Level of Education

Figure 2 also shows no demonstrated pattern of value perception among respondents based on level of education. The exception is the largely consistent high evaluation by respondents whose highest level of education was a high school degree.

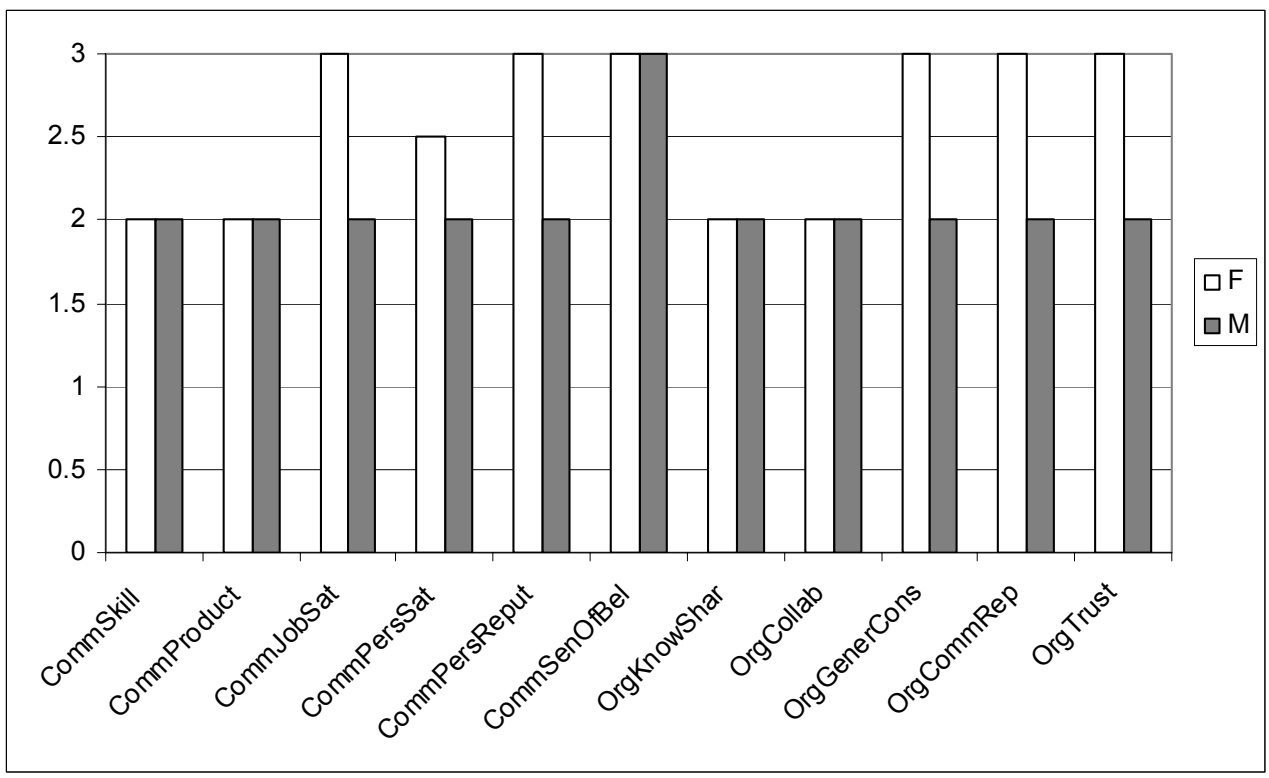

Figure 3: Participation in Technology Discussion Groups by Gender

Figure 3 demonstrates a difference in perceived value of participation in technology discussion groups among women and men. While men consistently evaluate the value of participating in a technology discussion group on all criteria other than establishing a sense of belonging within the community, women's evaluation of discussion groups is quite different. Women perceive more value in discussion groups for helping with job satisfaction, personal reputation, consensus generating within the organization, building a community reputation, and establishing organizational trust.

There were no demonstrated patterns of value perception by manner of technology education. 


\section{Conclusion}

Interestingly, women perceive a higher value in participating in discussion groups for social reasons more than problem solving or skill set development. It could be that all of these factors also contribute to their overall sense of belonging in the organization (their reputations, satisfaction, and trust in the company), while men experience a sense of belonging for another reason. Perrons (2002) suggested that for male IT professionals, many factors within the workplace (dominant numbers of males, male-oriented metaphors in training material, and gender statistics at the executive level) already contribute to a sense of belonging within an IT organization.

Women's use of technology as a social instrument (Gefen \& Straub, 1997; Ono \& Zavodny, 2005; Venkatesh \& Morris, 2000) also introduces opportunities to extend the benefits of technology discussion groups to an online medium, potentially making them more accessible, particularly to larger organizations with offices in a variety of locations. Gender was the only area where a significant difference was evident. This suggests that the results of this study could inform future research on the need for gender considerations in the implementation of online technology discussion groups to enhance general sense of belonging in an organization and also for technology problem solving and general training.

\section{References}

Ahuja, M.K. (2002). Women in the information technology profession: A literature review, synthesis and research agenda. European Journal of Information Systems, 11(1), 20.

Baroudi, J.J. \& Igbaria, M. (1995). An examination of gender effects on career success of information systems employees. Journal of Management Information Systems, 11(3), 181-202.

Benemati, J. and Lederer, A.L. (2001). Coping with rapid changes in IT. Communications of the ACM, 44(8), 83-88.

Dube, L., Bourhis, A., and Jacob, R. (2006). Towards a Typology of Virtual Communities of Practice. Interdisciplinary Journal of Information, Knowledge, and Management, 1, 69-93. Available at http://ijikm.org/Volume1/IJIKMv1p069-093Dube.pdf

Firth, D., Lawrence, C., and Clouse, S. (2006). Predicting Internet-based online community size and time to peak membership using the bass model of new product growth. Interdisciplinary Journal of Information, Knowledge, and Management, 1, p 1-12. Available at http://ijikm.org/Volume1/IJIKMv1p001012_Firth01.pdf

Fischer, A. (1998, February). Data communications stress survey: Is your career killing you? Data Communications, 53-64.

Francis, B. (2000). The gendered subject: Students' subject preferences and discussions of gender and subject ability. Oxford Review of Education, 26(1), 35-48.

Gefen, D. \& Straub, D.W. (1997). Gender differences in the perception and use of E-mail: An extension to the technology acceptance model. MIS Quarterly, 21(4), 389.

Harris, R. \& Wilkinson, M.A. (2004). Situating gender: students' perceptions of information work. Information Technology \& People, 17(1), 71.

Igbaria, M. \& Baroudi, J.J. (1995). The impact of job performance evaluations on career advancement prospects: An examination of gender differences in the IS workplace. MIS Quarterly, 19(1), 107-123.

Kaminski, J.A.M. \& Reilly, A.H. (2004). Career development of women in information technology. S.A.M. Advanced Management Journal, 69(4) 20.

Lee, D.M.S., Trauth, E.M., \& Farwell, D.W. (1995). Critical skills and knowledge requirements of IS professionals: A joint academic/industry investigation. MIS Quarterly, 19 (3) 313-332. 
Moore, J.E. (2000). One road to turnover: An examination of work exhaustion in technology professionals. MIS Quarterly, 24(1), 141-148.

Ono, H. \& Zavodny, M. (2005). Gender differences in information technology usage: A U.S.-Japan comparison. Sociological Perspectives, 48(1), 105.

Perrons, D. (2002). Gendered divisions in the new economy: Risks and opportunities. GeoJournal, 56(4), 271-280.

Ranson, G. \& Reeves, W.J. (1996). Gender, earnings, and proportions of women: Lessons from a high-tech occupation. Gender and Society, 10(2), 168-184.

Smits, S.J., McLean, E.R. \& Tanner, J.R. (1993). Managing high-achieving information system professionals. Journal of Management Information Systems, 9(4), 103.

Straub, D.W., \& Watson, R.T. (2001). Research commentary: Transformational issues in researching IS and net-enabled organizations. Information Systems Research, Fall 2001.

Sumner, M. \& F. Niederman. (2003). The impact of gender differences on job satisfaction, job turnover, and career experiences of information systems professionals. The Journal of Computer Information Systems. 44(2), 29-39.

Venkatesh, V. \& M.G. Morris. (2000). Why don't men ever stop to ask for directions? Gender, social influence, and their role in technology acceptance and usage behavior. MIS Quarterly, 24(1), 115-139.

\section{Biographies}

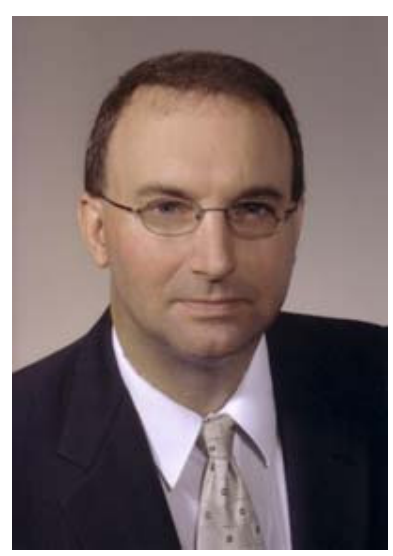

Brian H. Cameron is Assistant Professor of Information Sciences and Technology at The Pennsylvania State University. Prior to joining Penn State, he was Director of Information Technology for WorldStor, Inc., a storage service provider (SSP) in Fairfax, VA. He has also held a variety of technical and managerial positions within IBM and Penn State. His primary research and consulting interests include enterprise systems integration, storage networking, emerging wireless technologies, and the use of simulations and gaming in education. He has designed and taught a variety of courses on topics that include networking, systems integration, storage networking, project management, and IT consulting.

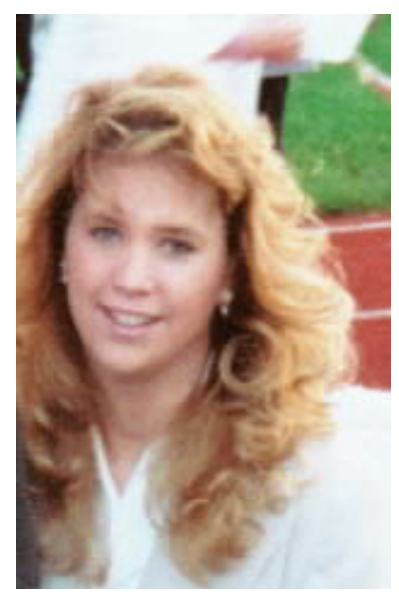

Loreen Marie Butcher-Powell is an Assistant Professor of Business Education and Office Information Systems at Bloomsburg University, Pennsylvania. Loreen has presented/published over 16 referred publications on pedagogy issues, and Information security. Recently, Loreen has also been a chapter author for many IS/IT books specializing in Networking. Loreen is on the International Board of Editors the Journal of Knowledge and Learning Objects, and the Journal of Information, Information Technology and Organizations. In 2004, Loreen received Bloomsburg University's Research and Development Grant 2005-2006, four Preparing Tomorrow's Teachers To Use Technology (PT3) Catalyst Mini Stipend Grants from Pennsylvania State System of Higher Education, Bloomsburg University, PA, USA, and the Phase I and Phase II Promoting Technology Adoption for Progress (PTAP) Grants from the Susquehanna Economic Development Association (SEDA) Council of Governors (COG), Lewisburg, PA, USA. 
She has also received the 2002 Teaching Academy Grant from Pennsylvania State University at Hazleton, PA, USA and was a 2002 committee member for the $\$ 100,000$ U.S.D. Common Wealth College Networking Mini-Grant at Pennsylvania State University, PA, USA. 